\title{
Victims of Violence in Accident \& Emergency: Reporting Survey of Eleven Emergency Structures Out of Eighteen
}

\author{
Maria Pia Ruggieri*, Anna Santa Guzzo**, Massimo Magnanti*, Giannantonio Cerqua* \\ *UOC Medicina I per l'Urgenza, Azienda Ospedaliera San Giovanni Addolorata di Roma \\ **UOC Medicina d’Urgenza e PS A.U. Policlinico Umberto $1^{\circ}$ Sapienza Università di Roma
}

\begin{abstract}
Sexual violence is a widespread and common phenomenon in our society, which unfortunately often goes unreported or undetected: a hidden "iceberg" of great dimension. Often the victims arrive to our emergency department where the sanitary workers are not prepared to help them professionally. By this work the authors want to evaluate health workers true understanding of the "problem of violence"; their human and professional capacity to manage it; their capacity to create
\end{abstract}

\section{Introduction}

Sexual violence is a widespread and common phenomenon in our society, which unfortunately often goes unreported or undetected: a hidden "iceberg" of great dimension. Different forms of rape, sexual abuse and blackmail exist, these can occur inside the family environment, externally or both (1).

When one speaks of "types of violence" one refers to the different forms of violence: physical (ill-treatment), sexual (molestation, rape, exploitation), psychological (violation of oneself), economical (denying access to the economic resources of the family, even if earned by the victim) $(2,3)$.

The 2006 ISTAT Survey, commissioned by the Ministry of Equal Rights and Opportunities $(4,5)$, has thrown light on some disturbing numerical data: from a sample of 25,000 women ranging in age from 16-70 years, $6,743,000$ were victims of physical or sexual violence (31.9\%); 5 million were victims of sexual violence (23.7\%); 3.961 .000 were victims of physical violence (18.8\%); 6.092 .000 were victims of psychological violence from their current partner (36.9\%); 1.100 .000 were victims of 'stalking', that is they had been constantly followed or harassed.

In 2006 there were 74 thousand reported cases of rape or attempted rape, $69.7 \%$ of these offences had been committed by the victims partner or ex-partner. Abuse at home is very common place but often these acts are not perceived as abuse.

Only $18.2 \%$ of victims are aware that the abuse they have endured are criminal offences, while $44 \%$ simply judge the abuse as 'something wrong' and $36 \%$ as 'something that happened'.

The proportion of episodes of violence which are reported is low $(12.4 \%)$. The proportion increases when women have contact with Accident and Emergency (62.3\%), Police, lawyers, and magistrates $(47.6 \%)$ and doctors or nurses $(35.9 \%)$.

Based on this epidemiological data, it was decided to conduct an investigation in the Accident and Emergency units (A\&E) and the Departments of Emergency and Admissions (DEA) in the Lazio Region. The aim of the investigation was to: evaluate health workers true understanding of the "problem of violence"; their human and professional capacity to manage it; their capacity to create and promote sensitisation and training programmes for professionals working in the field; and the ability to design and implement protocols and procedures to be utilized when managing victims of violence.

A questionnaire was distributed to nurses and doctors working in the critical areas (A\&Es and DEAs).

\section{Materials and Methodology}

A questionnaire was compiled and distributed to health professionals working in the critical areas (A\&E and DEA). The and promote sensitisation and training programmes for professionals working in the field; and the ability to design and implement protocols and procedures to be utilized when managing victims of violence by a questionnaire compiled and distributed to health professionals working in the critical areas (A\&E and DEA) in the region Lazio.

Keywords: sexual violence, victims of violence, critical areas, emergency department

questionnaire was divided into six distinct sections, each containing questions designed to illicit data regarding particular aspects.

The first section evaluated the subject population of the study by identifying: professional role - doctor or nurse, gender (male or female), age in years, number of years of experience working within the critical areas, the professional department they belonged to i.e. Accident \& Emergency, Department of Emergency and Admissions or other.

The second section evaluated health workers understanding of the problem of 'violence' by using the "triage colour code" system. This has been in use in all A\&Es and DEAs in the Lazio Region since 2008 (6), implemented following a training programme delivered by experts and the Public Health Agency. Thanks to the single triage model and a unique regional database system (GIPSE) used in all $A \& E S$ and DEAs it is possible to evaluate the competency of health workers through their attribution of the triage colour code system.

The third section evaluates the health workers level of understanding of the medical-legal aspects associated with the problem of 'violence' by utilising the indicator "referred to the judicial authorities (JA)", taking into account that the law requires "... an obligatory medical report to be made to the judicial authorities to include contributions from all health professionals who have assessed or treated the referent". The fourth section evaluates how the organization perceives and manages the problem "violence", whether there is a management model in place for victims of violence and if so whether it is general knowledge to all the health workers in the structure. This evaluation is conducted using the indicator "presence/absence of management protocol for victims of abuse".

The fifth section evaluates the specific "violence" training for health workers through the indicator "attendance/non-attendance at specific related training".

The sixth and final section evaluates the sensibility of health workers towards dealing with this area through the indicator "proposal to improve/correct".

The questionnaire was distributed by colleagues doctors from Head Office SIMEU Lazio of different hospitals to 330 health professionals working in the critical areas, included doctors, nurses and midwifes.

\section{Results}

Eleven structures out of a possible eighteen (61\%) agreed to participate in the survey (2 A\&E units, 7 DEAs level I and 2 DEAs level II) four of these were situated in the provinces of Rome and the remainder in the city itself. A total of 330 questionnaires were distributed, of these 293 (89\%) were compiled and returned. The subject sample who participated in the survey included doctors, 


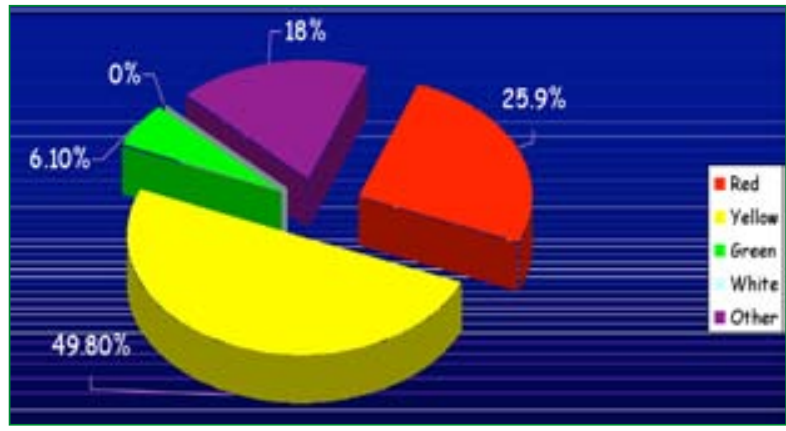

Figure 1 - Results "Triage Colour Codes awarded for reported or overt violence". \% Triage "Reported or Overt Violence"

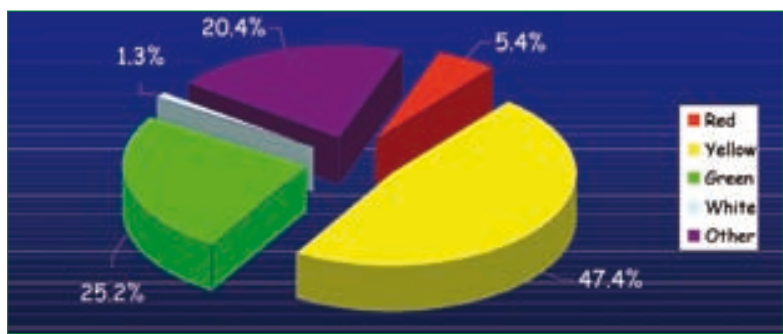

Fgure 2 - Results "Triage Colour Codes awarded for Suspected Violence". \% Triage "Suspected Violence"

nurses and midwifes, who had an average age of 40 and an average of 8.96 years work experience in the critical area under observation. Analysing the correct award of colour codes in accordance with the Lazio Triage Model (LTM), for a patient with "reported or overt violence", $49.8 \%$ of the questionnaire respondents awarded code yellow, $25.9 \%$ code red and $6.1 \%$ code green (see figure 1) (7) this represents an evident underestimate of the importance of this category compared to the LTM where a patient with "reported or overt violence" corresponds to a priority code red (see figure 2) (7). The colour code awarded for a patient with "suspected violence" also resulted in errors compared to the requirements of the LTM where "suspected violence" corresponds to a priority yellow code (see appendix $\mathrm{n}^{\circ} 1$ ) (6), however, $47.4 \%$ of the questionnaire respondents awarded code yellow, 5.4\% code red, $25.2 \%$ code green and $1.3 \%$ code white (see figure 3) (7).

Half of the health workers participating in the survey believed that referral to the Judicial Authorities was the sole responsibility of a doctor, $41 \%$ believed it was the sole responsibility of a nurse and 9\% did not express an opinion.

From the returned questionnaires it emerged that 7 of the 11 $A \& E / D E A$ structures did not have a protocol for the management of victims of violence; where a protocol was in place not all of the health workers knew of its existence; those who knew of its existence were unsure whether the protocol had been approved by the Hospital Mangers, by the Chief Physician or both.

Only $21.8 \%$ of the health workers reported that they had received an adequate training in the field of "violence", whilst $53.9 \%$ believed they had an adequate psychological attitude to receive victims; unfortunately, however, only $25.5 \%$ suggested or proposed alternatives or improvements to the way victims of violence are managed; those received included:

- Training for the health workers with "Telephone Rosa";

- The creation of a direct route for victims from A\&E to structures in the area;

- Sensitisation and training to be constant and continuous for health workers in A\&E;
- Reception of victims of violence by health workers in $A \& E$ to maximise trust.

The request for better information, also from hospitals where specific protocols have been put in place, where often the implementation of the protocol is inhibited by poorly trained health workers or the complete absence of dedicated space.

\section{Discussion}

From analysing the data gained from the questionnaire it emerged that medical and nursing staff who work in A\&Es and DEAs in the Lazio Region, even though middle-aged and with good relevant work experience, lack the technical, professional and relationship training to successfully manage victims of violence. This scarcity in training together with a work context where too often protocols for the management of victims of violence are inexistent protocols which should be foreordained, shared and implemented by the senior managers and chief physicians of the structures. This situation is unfortunately widespread within A\&Es and DEAs both within the city of Rome and its provinces. Furthermore, in spite of the methodology of the LTM, designed to protect possible and probable victims of violence, through the award of a code red or yellow to guarantee priority of treatment and cure, regardless if they are overt or suspected victims of violence and independent of whether their vital functions have been compromised, the triage nurses tend to underestimate these patients - proof of an enormous scarcity in sensibility and attention to duty from the health workers themselves and the health authorities more generally.

As regards possible limitations of the study and source of errors the authors think that the possible bias could be searched in the number of questionnaires distributed which are not known; certainly they were much more that those collected. But this is not so important for the finality of the study because even if the number of collected questionnaires is fewer, they have demonstrated:

1) the absolutely absence of protocols for the management of victims of violence,

2) where there is a protocol is unknown from medical and nursing staff who work in A\&Es and DEAs,

3) the absence of uniformity about the colour of triage, even if there is a regional sanitary educational and training project about triage from years.

\section{Conclusions}

In the view of the authors, which is supported by national and international experience reported in research literature (8-10), this situation could change through the constitution of a group of experts, doctors and nurses, working in the field of emergency treatment in

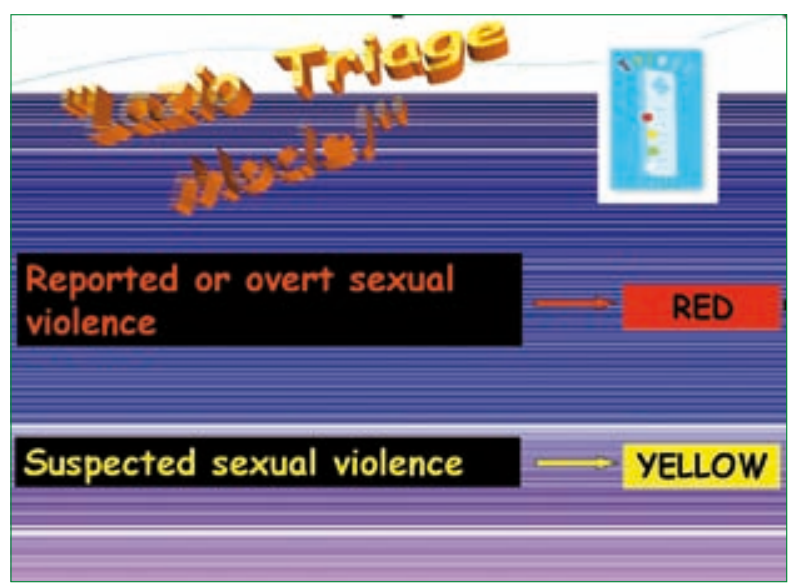

Figure 3 - Algorithm Lazio Triage Model 
the Lazio Region, committed to create, in collaboration with the relevant institutions and in particular the Public Health Agency:

a) a unique protocol for the management of victims of abuse to be implemented in all the Regions A\&Es and DEAs (both level I and II);

b) a training course, in collaboration with Voluntary Organisations and experts in the field, for all staff working in critical areas with periodical re-training;

c) a register of victims (data collection for active monitoring and quality control);

d) a network of assistance for victims after discharge from hospital to be organised in collaboration with anti-violence centres in Roma and its Provinces.

In addition the authors hope that with this project it will be possible to develop hearth workers' skills and ability to: identify, receive, listen to and initiate a helping relationship to respond to clinical and care needs of women who are victims of violence. In other words it is hoped that in the context of a dedicated diagnosis, care and treatment, violence becomes "a problem of Public Health, to be tackled with an interdisciplinary and scientific approach, that includes and integrates: medicine, epidemiology, sociology, psychology, criminology, education and economy" (11), a guarantee of ethics, humanity and professionalism.

\section{Bibliography}

1. Guidelines for medico-legal care for victims of sexual violence. (WHO) Geneva 2003.
2. Geneva Centre for the Democratic Control of Armed Forces (DCAF). Women in an Insecure World. Violence against Women. Facts, Figures and Analysis. Edited by Vlachovd and Lea Biason. 2005.

3. Muratore MG, Sabbadini LL. Italian survey on violence against woman. Statistical Journal of the United Nation ECE 22;2005:265-278.

4. Istat - Indagine Multiscopo, Sicurezza delle donne, 2006.

5. Istat. La violenza ed i maltrattamenti contro le donne dentro e fuori dalla famiglia 2006. Conferenza-evento a Palazzo Chigi, 2007.

6. Il Triage Ospedaliero, a cura del Gruppo "Triage Lazio" e Lazio Sanità Agenzia di sanità Pubblica. Edizione novembre 2007; pag. 148-150.

7. Ruggieri MP. La violenza sulla donna. IV Congresso Regionale SIMEU Nuove Prospettive Clinico-Organizzative; 20-21 novembre 2009 Roma.

8. Mincigrucci M. Gli strumenti di documentazione: il rapporto medico, i protocolli d'intesa. Servizio Consultoriale Azienda Sanitaria dell'Umbria USL n. 2.

9. Houry D, Cunningham RM, Hankin A, James T, Bernstein E, Hargarten S. Violence Prevention in the Emergency Department: Future Research Priorities. Academic Emergency Medicine 2009;16:1089-1095.

10. Linee Guida assistenza sanitaria, medico-legale, psico-sociale nelle situazioni di violenza alle donne e ai bambini, a cura del SVS "Soccorso Violenza Sessuale" Provincia di Milano. 2006.

11. World Report on Violence and Health, (WHO), Geneva 2002. 